\title{
Abundance and distribution of harbour porpoises Phocoena phocoena in selected areas of the western Baltic and the North Sea
}

\author{
M. P. Heide-Jørgensen ${ }^{1}$, J. Teilmann ${ }^{1}$, H. Benke ${ }^{2}$ \& J. Wulf ${ }^{2}$ \\ ${ }^{1}$ Danbiu ApS., Biological Consultants; Tornagervej 2, DK-2920 Charlottenlund, \\ Denmark \\ ${ }^{2}$ Forschungs- und Technologiezentrum Westküste, University of Kiel; Werftstraße 10, \\ D-25761 Büsum, Federal Republic of Germany
}

\begin{abstract}
An aerial survey of harbour porpoises, Phocoena phocoena, was conducted in JuneJuly 1992 in the western Baltic (Bay of Kiel, the Great Belt, Little Belt, an area north of Fyn) and a coastal area in the North Sea off the island of Sylt. Survey procedures and statistical analysis were identical to those of a similar survey in 1991 and survey results from the two years were compared. The highest density of porpoises was found in the North Sea area, whereas the Bay of Kiel and the Little Belt had low densities. The Great Belt and the area north of Fyn had intermediate densities and the area north of Fyn had a density similar to that found in the same area in 1991. The distribution of the perpendicular sighting distance from the surveys in 1991 and 1992 was identical in locality and dispersal, but gave rise to different estimates of effective search widths. Pod sizes for the 1992 survey were smaller than pod sizes estimated from boat surveys, but were within the range of those for the 1991 aerial survey.
\end{abstract}

\section{INTRODUCTION}

In an earlier paper (Heide-Jørgensen et al., 1992), we evaluated aerial survey as a means of estimating densities of harbour porpoises, Phocoena phocoena, as useful for monitoring population trends. We concluded that line transect methods applied with a target altitude of $183 \mathrm{~m}$ provide a reliable and effective way of estimating harbour porpoise densities. However, we also concluded that such surveys are sensitive to the type of aircraft used, experience of the observers and, most importantly, the sighting conditions under which the surveys are conducted. Also, the estimates of pod size are suspect, because in aerial surveys actual pod sizes may be underestimated. Estimates of pod sizes from incidental sightings from ships may be biased.

Surveys of harbour porpoises in Danish and German waters, conducted at regular intervals and using similar methods, are a possible way of evaluating trends in harbour porpoise populations. Monitoring of coastal harbour porpoise populations can be useful for assessing, albeit indirectly, the impact of porpoise by-catches in commercial fishing operations, and for evaluating the state of the marine environment.

The present survey was conducted to improve our estimations of the effective search width, to provide a more accurate estimate of the relative abundance of harbour porpoises in the western Baltic, to increase the area covered by surveys, and to test the feasibility of aerial surveys in the muddy, turbid waters of the Wadden and North Seas. 


\section{MATERIALS AND METHODS}

For the 1992 survey, five areas were selected, two of which were also covered by the 1991 survey. The Great Belt and Little Belt were included to ensure continuous sampling in the western Baltic, from the Bay of Kiel to the area north of Fyn (Fig. 1). In addition, an area around the island of Sylt in the North Sea, known for its conspicuous numbers of harbour porpoises, was chosen for testing the feasibility of aerial surveys in the relatively turbid nearshore waters of the North Sea (Fig. 2).

The survey in 1992 closely followed the design described in Heide-Jørgensen et al. (1992), except for all transects being flown at an altitude of $183 \mathrm{~m}$. The same aircraft was used as in 1991, and the average ground speed on 133 transects was $163 \mathrm{~km} / \mathrm{h}$ (95\% CI: 160-166). Observations were only made from the rear seats through the bubble windows; the right front seat was used only for training observers. The surveys were flown on the 17 th, 19th, 20th and 24th June in the area North of Fyn, the 19th and 30th June and 3rd July in the Little Belt, the 17th, 20th, 24th and 30th June in the Great Belt, the 27th-30th June in the Bay of Kiel, and the 3rd July in the North Sea. A total of 62 hours flying-time was allocated for the survey.

All flights were conducted in weather conditions that the observers judged excellent. Generally, this meant sea states less than 2. Flying was suspended if the sea state increased to more than 2 , or if the observers considered the conditions unsuitable. There was generally less than $4 / 8$ of cloud coverage, and for most of the survey the sky was clear. The weather conditions resembled those of the 1991 survey (Heide-Jørgensen et al., 1992).

Statistical analysis generally followed the procedures outlined by Burnham et al. (1980) with modifications as given in Heide-Jørgensen et al. (1992). All sightings from the rear seats in 1991 and 1992 were pooled across strata, to derive a common effective search half-width (ESW) for each year, and for both years. Sightings within $50 \mathrm{~m}$ of the trackline were discarded. The remaining sightings were truncated at a perpendicular distance of $500 \mathrm{~m}$, partitioned in $25 \mathrm{~m}$ intervals and fitted to the hazard rate model (Buckland, 1985) using the computer package "Distance" developed by Laake et al. (1991). Confidence intervals $(95 \%)$ were calculated using the method developed by Burnham et al. (1987).

Revised estimates (i.e. excluding right-front observers) for 1991 for the Bay of Kiel and the area north of Fyn were calculated, as well as new estimates for both areas, the Great Belt, the Little Belt and the North Sea area around the island of Sylt. Two methods of calculating densities were applied: Method 1: sightings from all strata, and both years, were pooled to derive a common ESW. Method 2: sightings were pooled by stratum, but separated by year.

Pod sizes were estimated directly from the surveys in each stratum and year, or from collections of incidental sightings from sailors and ferry employees in Little Belt, Great Belt, the area north of Fyn, the Bay of Kiel (cf. Heide-Jørgensen et al., 1992) and the Wadden Sea. For this last area, the data on pod sizes were obtained during 1989-1992, when the University of Kiel had a programme to collect incidental sightings made in German waters of the North Sea.

Glare was quantified as the angle from the heading of the aircraft at which observation became obstructed by reflections of the sun on the sea's surface. A one-tailed paired 


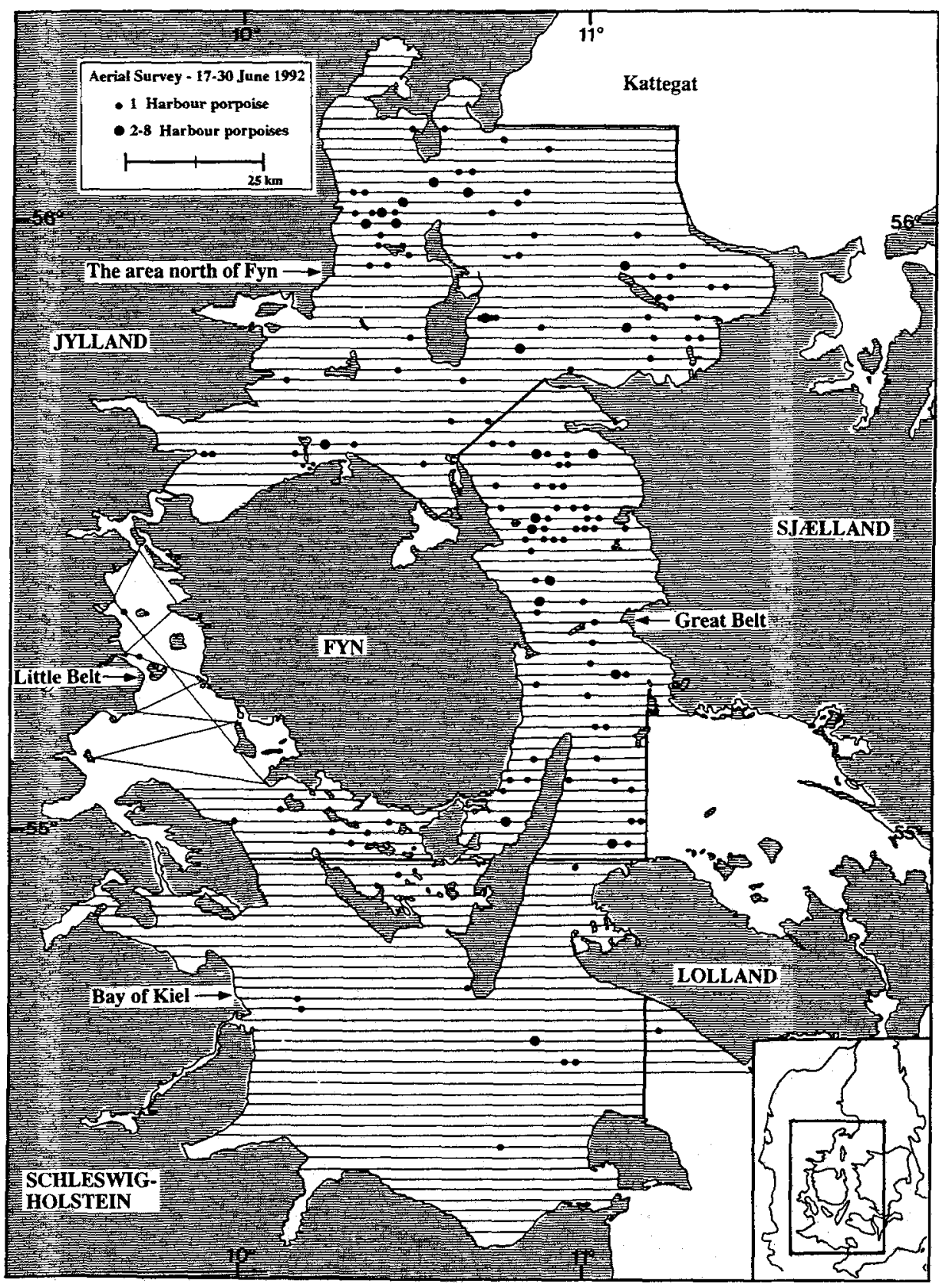

Fig. 1. Map of the area in the western Baltic Sea with transects and sightings of harbour porpoises indicated. 1 Harbour porpoise; $\bullet 2-8$ Harbour porpoises. Aerial survey from 17-30 June 1992 


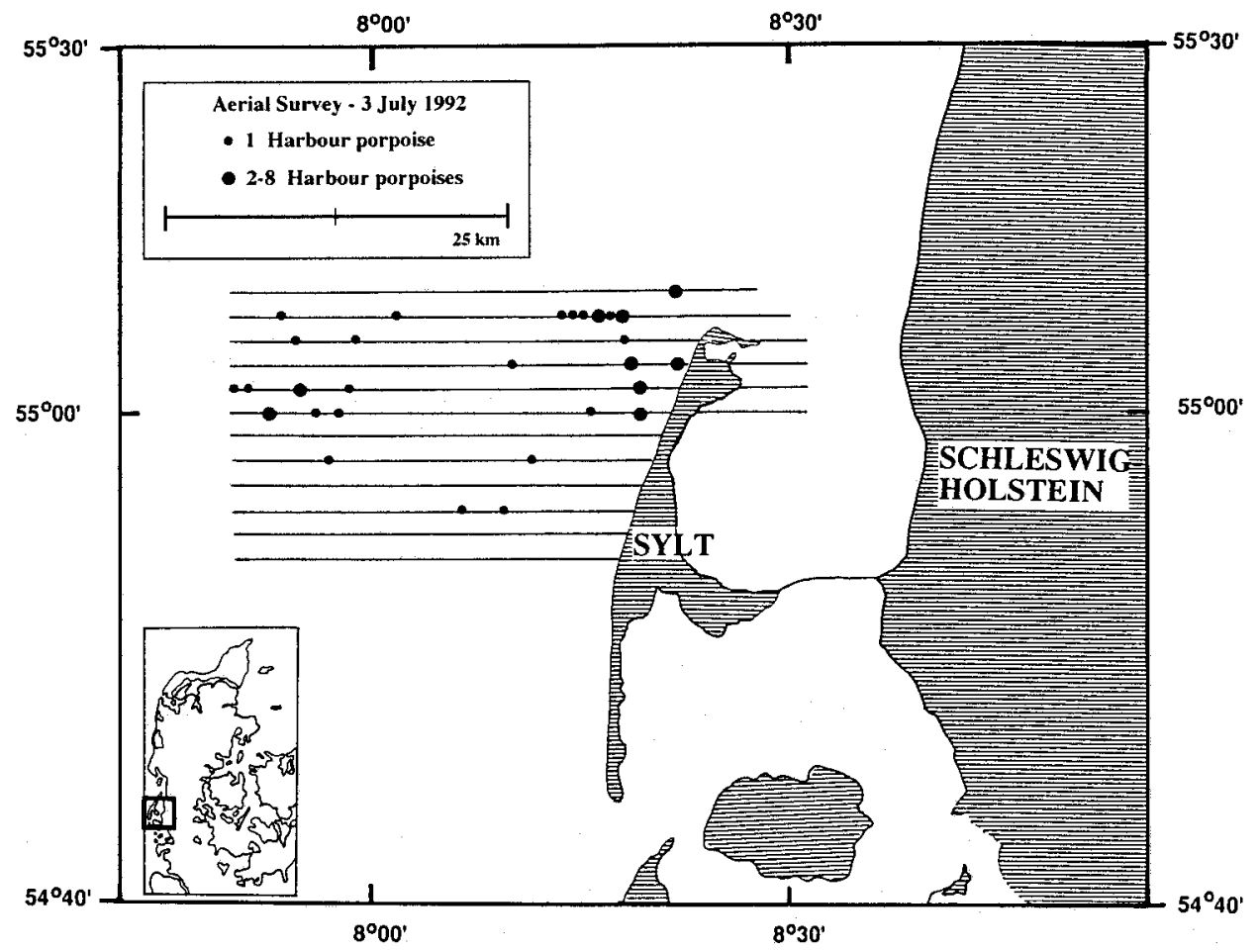

Fig. 2. Map of the area in the North Sea with transects and sightings of harbour porpoises indicated. - 1 Harbour porpoise; - 2-8 Harbour porpoises. Aerial survey on 3rd July 1992

t-test was used to compare the number of porpoises sighted per linear kilometer on the side with glare, to the number sighted on the side without glare.

For each sighting, an effort was made in both 1991 and 1992 to include information about the sighting cue (e.g. if the porpoise was at or below the surface when first observed). Also, the reaction by porpoises to the passage of the aircraft, the presence of a calf within a body length of an adult and the presence of gulls near porpoises. Such ancillary data from both years are presented here.

\section{RESULTS}

The survey in 1992 covered 5722 linear kilometers dispersed over the Bay of Kiel, the Great Belt, the Little Belt, the area north of Fyn and a selected area in the North Sea around the island of Sylt (Figs 1,2). This effort resulted in a total of 214 encounters with harbour porpoises, including sightings by the pilot and the right-front observer, and those made by rear observers that were more than $500 \mathrm{~m}$ from the trackline. The highest density of pods was in the North Sea, where the sighting rate was almost 10 times greater than the lowest density found in the Bay of Kiel (Tables 1, 2).

The highest frequency of mother-calf pairs was also found in the North Sea area where $28 \%$ of the sightings were of mother-calf pairs. In the Great Belt and the area 


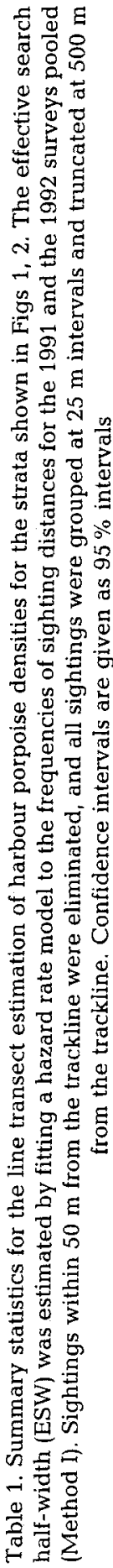

\begin{tabular}{|c|c|c|}
\hline 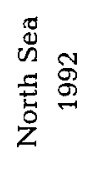 & 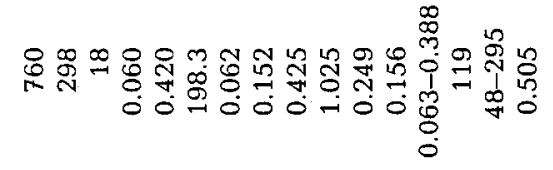 & 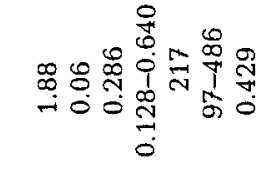 \\
\hline 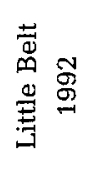 & 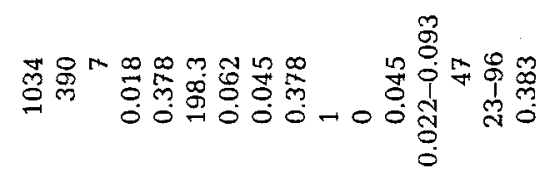 & 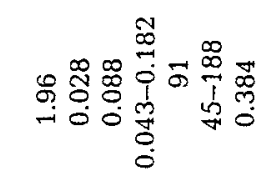 \\
\hline 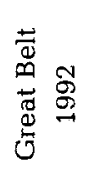 & 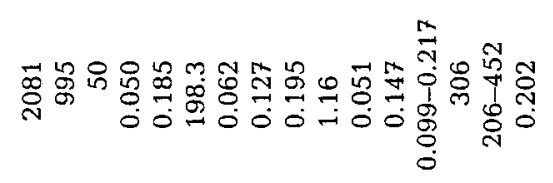 & 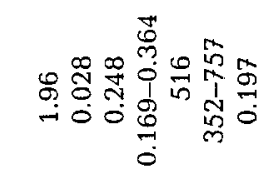 \\
\hline & 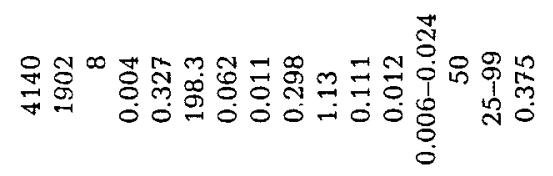 & 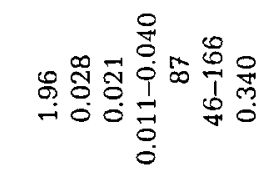 \\
\hline 窝 & 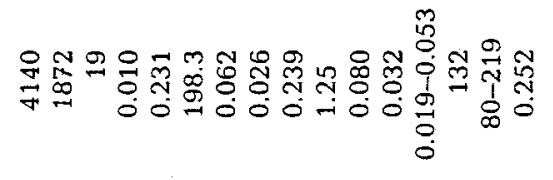 & 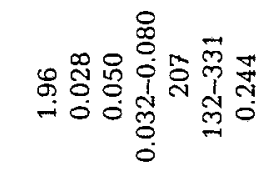 \\
\hline 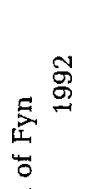 & 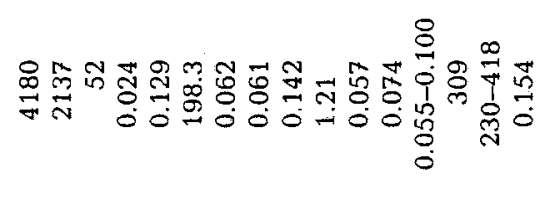 & 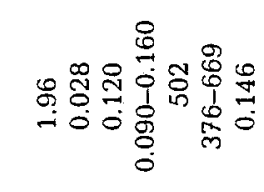 \\
\hline $\overrightarrow{\mathrm{Z}}$ & 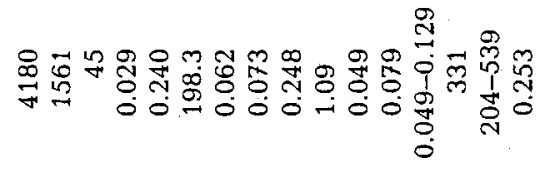 & 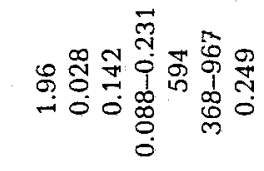 \\
\hline 总 & 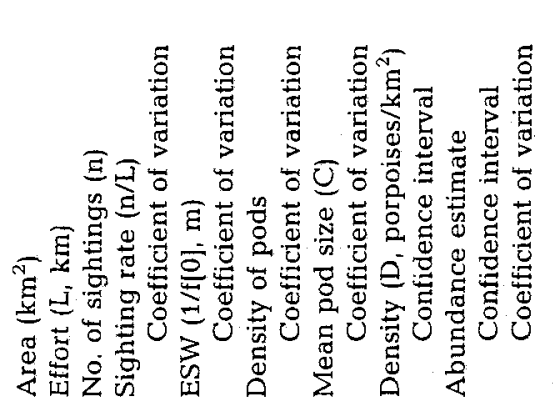 & 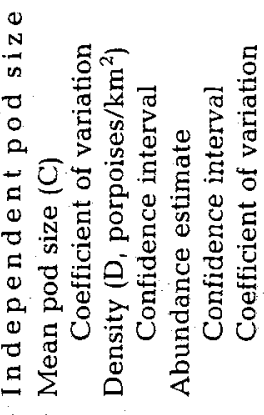 \\
\hline
\end{tabular}


Table 2. Summary statistics for the line transect estimation of harbour porpoise densities for two of the strata shown in Fig. 1. The effective search half-width (ESW) was estimated by fitting a hazard rate model to the frequencies of sighting distances for the 1991 and the 1992 survey separately (Method 2). Sightings within $50 \mathrm{~m}$ from the trackline were eliminated, and all sightings were grouped at $25 \mathrm{~m}$ intervals and truncated at $500 \mathrm{~m}$ from the trackline. Confidence intervals are given as $95 \%$ intervals. See Table 1 for comparison, and for additional information on effort and sightings

\begin{tabular}{|lcccc|}
\hline Area & \multicolumn{2}{c}{ North of Fyn } & \multicolumn{2}{c|}{ Bay of Kiel } \\
Year & 1991 & 1992 & 1991 & 1992 \\
\hline ESW (1/ff0], m) & 165.8 & 223.2 & 165.8 & 223.2 \\
Coefficient of variation & 0.095 & 0.070 & 0.095 & 0.070 \\
Density of pods & 0.087 & 0.055 & 0.031 & 0.009 \\
$\quad$ Coefficient of variation & 0.248 & 0.147 & 0.250 & 0.334 \\
Density (D, porpoises/km $\left.{ }^{2}\right)$ & 0.095 & 0.067 & 0.039 & 0.010 \\
Abundance estimate & 397 & 280 & 162 & 41 \\
$\quad$ Confidence interval & $339-465$ & $205-380$ & $99-268$ & $21-81$ \\
Coefficient of variation & 0.262 & 0.157 & 0.262 & 0.352 \\
\hline
\end{tabular}

north of Fyn, less than $2 \%$ of the sightings were of mother-calf pairs. Of the relatively few sightings from the Bay of Kiel and the Little Belt in 1992, none were mother-calf pairs. In $1991,18 \%$ of 22 sightings from the Bay of Kiel, and $4 \%$ of 85 sightings from north of Fyn +were of mother-calf pairs.

G la re. There was no significant difference in the number of porpoises sighted per linear kilometer, for transects with glare angles of less than $55^{\circ}(\mathrm{p}>0.08)$. However, for those with angles of glare betweeen $55^{\circ}$ and $110^{\circ}$, the number of porpoises sighted per kilometer was significantly lower on the side with glare $(p=0.0027)$. We therefore omitted the side with glare on all transects having an angle of glare greater than $55^{\circ}$.

Effect of sea state. Sea state has a negative effect on the probability of observing harbour porpoises. We purposely avoided sea states above 1, but short periods with sea state 2 could not be completely avoided. Such conditions sometimes occurred along coasts with turbulence, or in exposed offshore areas. The total efforts as well as the number of sightings in sea state 2 were low (<21\%) during both the 1991 and the 1992 survey (Table 3). However, the distribution of the effort and sightings in 1991 on sea state was significantly different from the 1992 distribution (chi-square, $\mathrm{df}=2, \mathrm{p}=0.0001$ ).

No difference in ESW and median values could be detected for sightings in sea state 0 and 1 (Table 3, Fig. 3). The ESW in sea state 2 was significantly narrower than in sea states 0 and 1 (Table 3, Fig. 3). This clearly demonstrates that there is a risk associated with using survey data collected in sea state 2 . However, less than $13 \%$ of the sightings in our surveys were made in sea state 2 conditions, and the effect on the ESW is therefore considered to be negligible.

Observer efficiency. During both the 1991 and 1992 surveys, a combination of experienced and inexperienced observers was used, but only one of the observers had a sufficient number of sightings to allow a comparison of efficiency between years. This observer increased the area of his search swath considerably in 1992, whereas the search swath for all other observers combined only increased slightly (Table 4). Because the 
Table 3. Distribution of sightings and effort on sea states, median of the frequency of perpendicular distances and effective search half-width (ESW) calculated for the three sea state conditions, following the procedures employed for the pooled distance frequency (i.e. hazard rate, left and right truncation at 50 and $500 \mathrm{~m}$, respectively, and $25 \mathrm{~m}$ intervals). Coefficients of variation are given in parentheses. See Fig. 3 for distribution of the sightings of perpendicular distances

\begin{tabular}{|c|c|c|c|c|c|c|}
\hline & \multicolumn{2}{|c|}{$\begin{array}{l}\text { Percentage } \\
\text { of sightings }\end{array}$} & \multicolumn{2}{|c|}{$\begin{array}{c}\text { Percentage } \\
\text { of effort }\end{array}$} & \multirow{2}{*}{$\begin{array}{c}\text { Median } \\
\text { sighting distance } \\
\text { (m) }\end{array}$} & \multirow{2}{*}{$\begin{array}{l}\text { ESW } \\
\text { (m) }\end{array}$} \\
\hline & 1991 & 1992 & 1991 & 1992 & & \\
\hline Sea state 0 & 59 & 34 & 46 & 20 & 138 & $\begin{array}{c}209 \\
(0.08)\end{array}$ \\
\hline Sea state 1 & 39 & 54 & 42 & 60 & 133 & $\begin{array}{c}204 \\
(0.09)\end{array}$ \\
\hline Sea state 2 & 2 & 12 & 12 & 20 & 91 & $\begin{array}{c}79 \\
(0.84)\end{array}$ \\
\hline
\end{tabular}

observer who increased his search swath in 1991 contributed substantially to the total number of sightings in both years, the much wider ESW achieved in 1992 is probably due mainly to this observer's increased efficiency (Table 2, Fig. 4).

Comparison of densities in 1991 and 1992 . Two methods of calculating densities were applied:

Method 1: both the 1991 and 1992 surveys used the same aircraft (with observations from the rear seats), the same altitude of $183 \mathrm{~m}$ and at least some of the same observers. The two surveys can therefore be considered comparable, with respect to the perpendicular distance distribution of the sightings. In both years, there was a dearth of sightings within the first $50 \mathrm{~m}$ on either side of the trackline, hence this area was not included in the calculation of area searched. Sightings more than $500 \mathrm{~m}$ from the trackline were considered to be outliers and were therefore omitted.

The frequency distributions of the perpendicular distance of the sightings in 1991 ( $\mathrm{n}=65)$ and $1992(\mathrm{n}=140)$ were compared with regard to locality and dispersion, and were not found to differ significantly (Kolmogorov-Smirnoff two sample test, $\mathrm{p}=0.13$ ) when comparing sightings from 50 to $500 \mathrm{~m}$ from the trackline in intervals of $25 \mathrm{~m}$.

The pooled sighting distances from 1991-92 were fitted to the hazard-rate model. The estimate of the ESW for the pooled data from 1991 and 1992 (ESW = 198.3, cv 0.062) was intermediate between the search width for 1991 (ESW $=165.8 \mathrm{cv} 0.09$ ) and 1992 (ESW $=223.2$, cv 0.07, Fig. 4). The common ESW for both 1991 and 1992 was applied to the density estimation in all areas for both years (Table 1).

Method 2: alternatively, the two surveys could be treated as two independent samples, with each integrating the variations of observer efficiency and sighting conditions. There are obvious differences in observer efficiency and sighting conditions between the two years, so separate ESW's could be applied for each year (Table 2).

The two methods of deriving the ESW gave markedly different abundance estimates in the two strata where the surveys can be compared (the area north of Fyn and the Bay of Kiel). Method 1 provides identical estimates for the area north of Fyn in both years, 


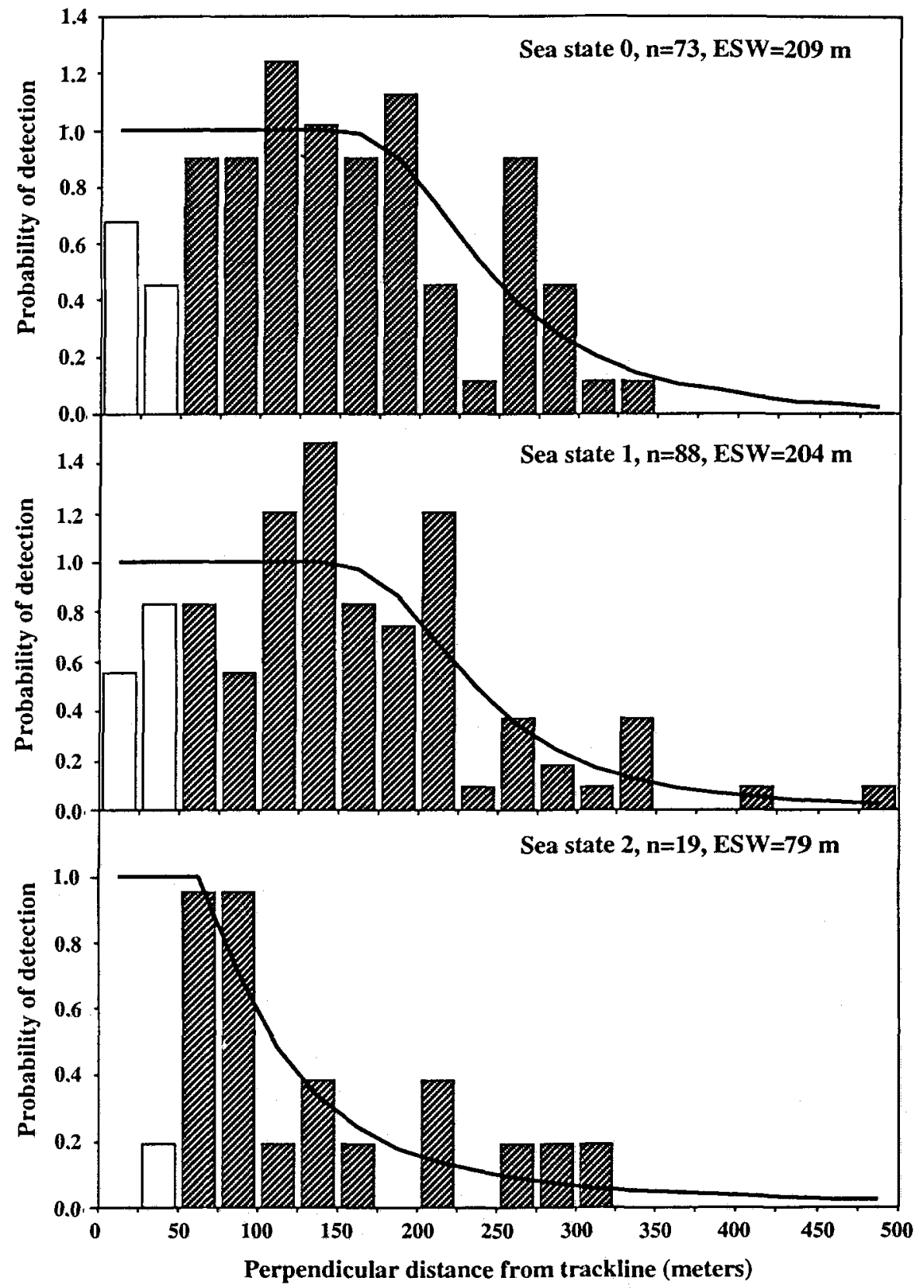

Fig. 3. Distribution of sightings of harbour porpoises at various distances from the trackline for sea state 0 to 2 (1991 and 1992 pooled). Data were fitted to the hazard rate model (Buckland, 1985) and the fitted curve shows the expected number of sightings 
Table 4. Comparison of proportion of sightings, effective search half-width (ESW) and median of the frequency of perpendicular distances, for one observer that changed search swath between 1991 and 1992 with all the other observers. Confidence intervals $(95 \%)$ given in parentheses

\begin{tabular}{|lcccc|}
\hline & \multicolumn{2}{c}{ One observer } & \multicolumn{2}{c|}{$\begin{array}{c}\text { All other observers } \\
\end{array}$} \\
& 1991 & 1992 & 1991 & 1992 \\
\hline Proportion of all sightings & $33 \%$ & $40 \%$ & $67 \%$ & $60 \%$ \\
ESW $(\mathrm{m})$ & 161 & 268 & 152 & 189 \\
Median $(\mathrm{m})$ & $(85-304)$ & $(219-327)$ & $(126-184)$ & $(156-230)$ \\
& 114 & 159 & 133 & 128 \\
\hline
\end{tabular}

whereas method 2 indicates a $30 \%$ decline in abundance from 1991 to 1992. Both methods suggest that there were significantly fewer porpoises in the Bay of Kiel in 1992, compared with 1991.

Observational cues. For about half the sightings, note was taken as to whether the porpoise was at the surface (breaking the surface) or below the surface, and whether it reacted to the passage of the aircraft by diving. The only clearly discernible reaction to the aircraft was diving; other types of reaction were not observed and recognised. All dives made during the passage of the aircraft were considered to be a reaction to the noise or shadow of the plane, even though other factors may have triggered at least some of the dives. Reactions after the passage of the aircraft could not be observed, because our visual search was limited to the area from $0^{\circ}$ to $90^{\circ}$ on either side of the aircraft. The distribution of cues was very similar between 1991 and 1992 (Table 5). During the passage of the plane, at least half the porpoises were either resting at the surface or swimming while breaking the surface.

The porpoises were often accompanied by gulls (Larus fuscus and Larus ridibundus) that were either on the water surface or flying. These birds often attracted the attention of the observer to the spot of the water surface where the porpoise was swimming. Gulls were in the close vicinity of the porpoises in approximately $13 \%$ and $16 \%$ of the sightings in 1991 and 1992, respectively. However, associations with gulls were not consistently recorded and could also have been missed by the observers.

Table 5. Three cues noted for the harbour porpoise sightings

\begin{tabular}{lcc|}
\hline & $\begin{array}{c}1991 \\
(\mathrm{n}=55)\end{array}$ & $\begin{array}{c}1992 \\
(\mathrm{n}=113)\end{array}$ \\
\hline At surface & $62 \%$ & $57 \%$ \\
Below surface & $29 \% *$ & $32 \%$ \\
Dive reaction to passage of aircraft & $9 \%$ & $11 \%$ \\
two of them were swimming belly-up & & \\
* five of them were at the surface when diving & & \\
\hline
\end{tabular}




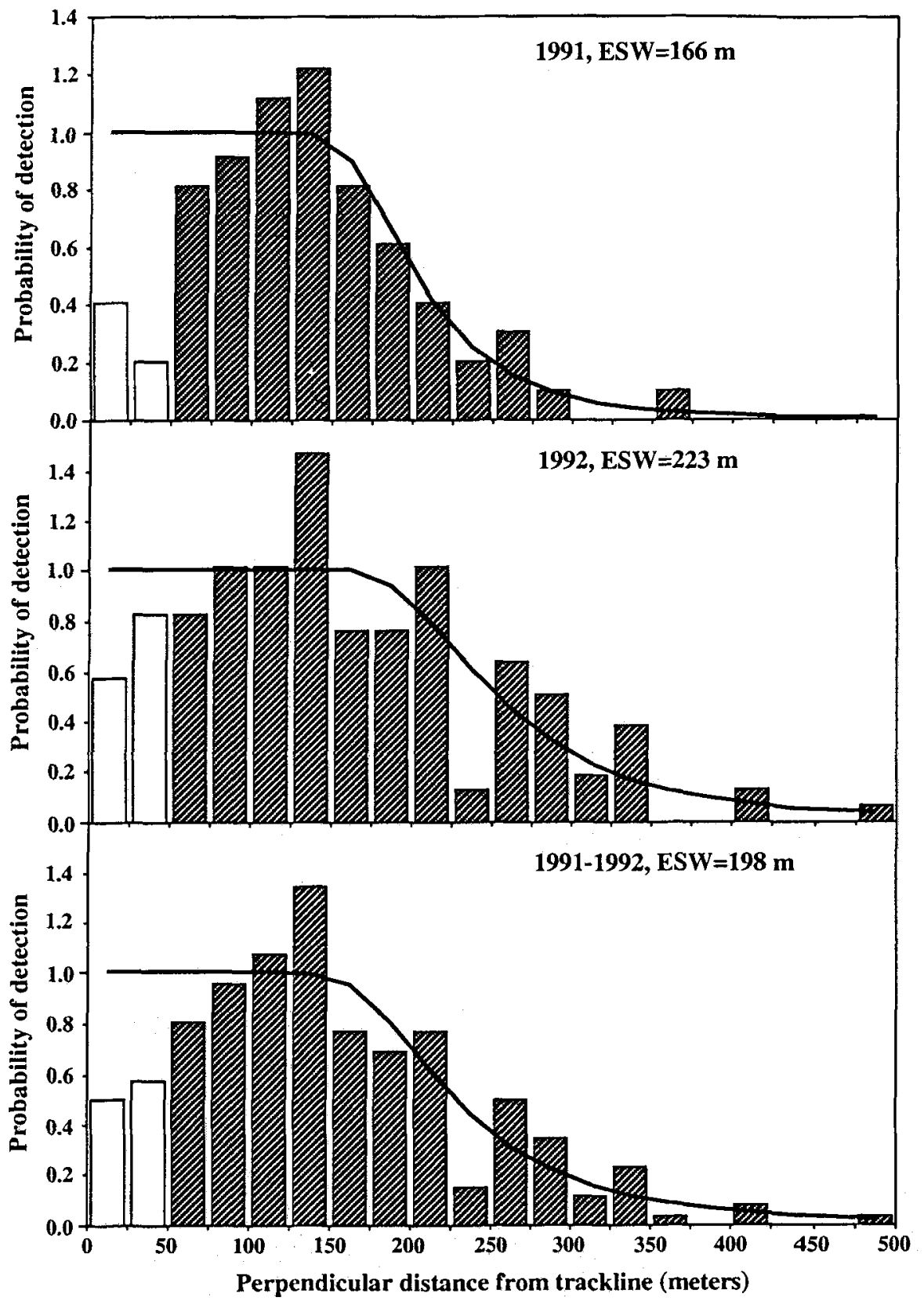

Fig. 4. Distribution of sightings of harbour porpoises at various distances from the trackline for both the 1991 and 1992 surveys (rear observers only). Data were fitted to the hazard rate model (Buckland, 1985) and the fitted curve shows the expected number of sightings 


\section{DISCUSSION}

Results of aerial surveys of harbour porpoises are evidently subject to considerable variability, depending on sighting conditions and observer efficiency. Previous studies have also demonstrated the importance of sighting conditions. For example, Barlow et al. (1988) noted that estimates of harbour porpoise density were negatively biased by increasing cloud coverage and sea states. The effect of variable observer efficiency could only be addressed in a limited way in the present study, due to the low number of sightings per observer. Nevertheless, our results indicate that, despite a slight increase in sea state in 1992, the observer who contributed the most sightings in both years widened his search swath significantly. Part of this apparent improvement may be due to the decision, taken after the 1991 survey, that the first $50 \mathrm{~m}$ from the trackline would be omitted from the analyses.

In the context of attempting to monitor trends in harbour porpoise densities, two mutually contradictory arguments for deriving ESW's seem equally appropriate:

(1) Ideally, sightings for each year and each stratum should be treated separately. This procedure takes account of the annual variability in observer efficiency and sea states when deriving the ESW's.

(2) The pooling of sightings across years and strata standardises and reduces the variance. This procedure recognises that confident estimation of variability is difficult when dealing with small sample sizes and flexible parameters such as sea state and observer efficiency. Also, the annual contribution to the variation should become progressively smaller.

Both approaches require that the surveys be conducted under similar conditions, e.g. identical survey platform, altitude, speed, sea states of 0 and 1, no cloud coverage. Given these restrictions, it is usually impossible to obtain adequate samples when calculating ESWs for each year, stratum, and perhaps even day. Integration of distance data over several years will, under the same restrictions, allow a reliable and confident generalisation of the search profile to be made. The disadvantage of such integration is that it requires the updating of all past surveys when a new survey is added. However, as the number of surveys increases, the adjustments of past surveys eventually becomes trivial.

Regardless of the method employed, densities of harbour porpoises in the Bay of Kiel are low compared with all other areas surveyed. The later timing of the survey in the Bay of Kiel in 1991 (July) may explain the higher densities found in 1991 than in 1992. No surveys were conducted in the Great Belt in 1991 and we cannot exclude the possibility that the porpoises found in the Great Belt in June 1992 would have moved south into the Bay of Kiel in July. However, although the porpoises observed in the Great Belt were close to the northern border of the stratum in the Bay of Kiel, nothing indicates that they moved into this stratum during the survey period. The Bay of Kiel was surveyed as long as ten days after the Great Belt, but densities in the Bay remained low.

A ship-based survey in September 1991 (covering both the Bay of Kiel and the southern part of the Great Belt) confirmed that the Great Belt has a much higher density of harbour porpoises than the Bay of Kiel at that time of year (Benke, unpubl. data).

Like the Bay of Kiel, the Little Belt has a density of porpoises that is close to the detection limits, even though it was formerly an area where large numbers of porpoises could be caught in a drive fishery (Andersen, 1982). 
The 1992 study demonstrated that aerial survey is a feasible method for censusing harbour porpoises in the North Sea close to the coast, and that high densities of harbour porpoises are present around the island of Sylt. Also, a remarkably large proportion of the mother-calf pairs that were observed during the surveys were around the island of Sylt. The area was chosen because of the many observations of harbour porpoises made along the coast of Sylt (Benke, unpubl. data). It is important to stress that the densities obtained from this survey cannot be applied to the entire North Sea, because the area selected is considered to have especially high densities.

Independent estimation of pod sizes for each stratum and year remains an intriguing problem, as pod-size estimates pooled over several years and areas may mask possible trends between years. For trend analysis, it is therefore preferable to have independent estimates of pod sizes, or to make uncorrected comparisons of densities of pods.

Future surveys will necessarily have some variation caused by suboptimal sighting conditions (i.e. sea state 2), and of participating observers with various levels of experience. To enhance comparability, analyses of future surveys should not include more than $10 \%$ of sightings from sea state 2 and should include none from higher sea states.

Acknowledgements. Besides the authors, the following participated as observers: R. Dietz, P. Paludan Moller, 1. Petersen, J. Refn, R. Sonntag. K. Hüllert prepared the maps; L. Petersen (Danish Air Survey ApS.) was the pilot on both surveys; P. Agger, S. Buckland and R, Reeves kindly provided criticism of an earlier draft of this manuscript. The Danish part of this study was financed by the National Forest and Nature Agency (Danish Ministry of Environment) and the German part by Greenpeace Germany (1991) and the Ministry of Environment, Nature Conservation and Nuclear Safety.

\section{LITERATURE CITED}

Andersen, S. H., 1982. Change in the occurrence of the harbour porpoise, Phocoena phocoena, in Danish waters as illustrated by catch statistics from 1834 to 1970 . - F. A. O. Fish. Ser, 5 (4), 131-133.

Barlow, J., Oliver, C. W., Jackson, T. D. \& Taylor, B. L., 1988. Harbor porpoise, Phocoena phocoena, abundance estimation for California, Oregon, and Washington: II Aerial surveys. - Fish. Bull. U.S. $86,433-444$.

Buckland, S. T., 1985. Perpendicular distance models for line transect sampling. - Biometrics 41 , $177-195$.

Burnham, K. P., Anderson, D. R. \& Laake, J. L., 1980. Estimation of density from line transect sampling of biological populations. - Wild. Monogr., Chestertown, 72, 1-203.

Burnham, K. P., Anderson, D. R., White, G. C., Brownie, C. \& Pollock, K. H., 1987. Design and analysis methods for fish survival experiments based on release-recapture. - Am. Fish. Soc., Bethesda, Maryland, $437 \mathrm{pp}$.

Heide-Jørgensen, M.-P., Mosbech, A., Teilmann, J., Benke, H. \& Schultz, W., 1992. Harbour porpoise (Phocoena phocoena) densities obtained from aerial surveys north of Fyn and in the Bay of Kiel. - Ophelia 35, 133-146.

Laake, J. L., Buckland, S. T., Anderson, D. R. \& Burnham, K. P., 1991. Distance sampling: Abundance estimation of biological populations. Colorado Coop. Fish and Wildlife Res. Unit, Colorado State Univ., Fort Collins, Colorado, $53 \mathrm{pp}$. 